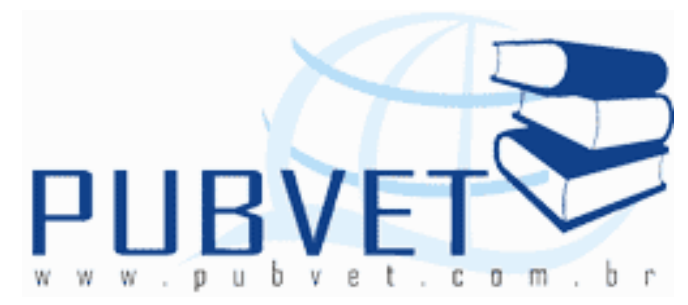

PUBVET, Publicações em Medicina Veterinária e Zootecnia.

\title{
Parâmetros termorreguladores e variáveis ambientais de ovinos em diferentes épocas do ano no sul do Estado do Piauí
}

Carlos Syllas Monteiro Luz ${ }^{1}$; Cícero Pereira Barros Júnior ${ }^{1}$; Wéverton José Lima Fonseca ${ }^{1}$; Gioto Ghiarone Terto e Sousa ${ }^{2}$; Karina Rodrigues Santos ${ }^{4}$; Severino Cavalcante de Sousa Júnior ${ }^{3}$

${ }^{1}$ Graduandos do Curso de Zootecnia, Universidade Federal do Piauí, (UFPI/Bom Jesus).

${ }^{2}$ Pós-Graduando em Ciência Animal, Universidade Federal do Piauí, UFPI, Teresina.

${ }^{3}$ Zootecnista, Dr., Universidade Federal do Piauí, (UFPI/Bom Jesus).

${ }^{4}$ Médica Veterinária, Dra., Universidade Federal do Piauí, (UFPI/Bom Jesus).

\section{Resumo}

O presente trabalho buscou avaliar os parâmetros de regulação térmica e variáveis ambientais de ovinos da raça Santa Inês e Morada Nova durante os turnos da manhã e tarde, nos períodos seco e chuvoso, e mostrar a influencia do clima sobre os mecanismos de troca de calor de ovinos. A pesquisa foi desenvolvida no campus Professora Cinobelina Elvas da Universidade Federal do Piauí (UFPI). Foram utilizados cinco ovinos da raça Santa Inês e cinco da raça Morada Nova com intuito de mensurar a temperatura retal (TR), frequência respiratória (FR) e a taxa de sudação (TS). Os animais foram medidos em dois turnos, às $9 \mathrm{~h}$ e às $15 \mathrm{~h}$, durante o período seco (agosto á 
LUZ, C.S.M. et al. Parâmetros termorreguladores e variáveis ambientais de ovinos em diferentes épocas do ano no sul do estado do Piauí. PUBVET, Londrina, V. 6, N. 35, Ed. 222, Art. 1474, 2012.

novembro) e chuvoso (janeiro á maio). Nos mesmos horários o ambiente foi monitorado quanto à temperatura do $\operatorname{ar}(\mathrm{TA})$ e umidade do ar (UA) e Índice de Temperatura de Globo e Umidade (ITGU). UA, TA e ITGU obtiveram diferença a $(P<0,05)$ de significância para os períodos, no entanto a UA e ITGU não diferenciaram a $(P<0,05)$ nos turnos da coleta. Não foi verificado efeito significativo $(P<0,05)$ da FR e TS entre os turnos e períodos de coleta. Já a TR diferenciou a $(P<0,05)$ em turnos e períodos, aonde no período seco atingiu $\left(39,40^{\text {aa }}\right)$ e no chuvoso foi de $\left(38,91^{\text {ab }}\right)$ respectivamente para os turnos da tarde. Constatou-se nesse estudo que os ovinos mostraram-se adaptados em relação às mudanças climáticas de período, contudo, apresentaram maior aquecimento corporal e termólise evaporativa nos turnos da tarde.

Palavras-chave: frequência respiratória, taxa de sudação, umidade do ar.

\section{Thermoregulatory parameters and environmental variables of sheep in different seasons in the southern state of Piauí}

\section{Abstract}

This study aimed to evaluate the parameters of thermal regulation and environmental variables of Santa Ines sheep and Morada Nova during the morning and afternoon during the dry and rainy, and show the influence of climate on the mechanisms of heat exchange sheep. The research was conducted on campus Teacher Cinobelina Elvas Federal University of Piauí (UFPI). We used five sheep Santa Ines and Morada Nova five in order to measure the rectal temperature (RT), respiratory rate (RR) and sweating rate (SR). The animals were measured in two rounds at 9 am and $15 \mathrm{pm}$, during the dry season (August to November) and rainy season (January to May). In the same time the environment was monitored for temperature (TA) and humidity ( $A U$ ) and index and the Globe and Humidity Temperature (BGT). AU, TA and BGT obtained difference $(P<0.05)$ for the periods of significance, but the $A U$ and the BGT did not differ $(P<0.05)$ shifts in the collection. There was no significant effect $(P<0.05)$ for RF and TS between shifts and periods of 
LUZ, C.S.M. et al. Parâmetros termorreguladores e variáveis ambientais de ovinos em diferentes épocas do ano no sul do estado do Piauí. PUBVET, Londrina, V. 6, N. 35, Ed. 222, Art. 1474, 2012.

collection. As for the TR differed $(\mathrm{P}<0.05)$ and shift periods, where the dry season reached (39.40 pa) and was in the rainy ( $a b 38.91$ ) respectively for the afternoon shift. It was found that sheep in this study proved to be adapted in relation to climate change of period, however, had higher body heat and evaporative heat loss in the later rounds.

Keywords: humidity, respiratory rate, sweating rate.

\section{Introdução}

O rebanho de ovinos no nordeste é representado por um efetivo de aproximadamente 9,85 milhões de cabeças (IBGE, 2010). A maioria dos rebanhos de ovinos nordestinos é explorada em sistema extensivo não sendo utilizadas práticas adequadas de manejo alimentar, sanitário e reprodutivo, aspectos que influenciam diretamente na estagnação desses rebanhos ao longo dos anos, a despeito da rusticidade e da adaptabilidade dessas espécies à região.

A capacidade adaptativa de ovinos em ambientes tropicais é um fator importante na produção desses animais em regiões mais quentes no brasil. Um ambiente é considerado confortável quando o animal está em equilíbrio térmico com o mesmo, ou seja, o calor produzido (termogênese) pelo metabolismo animal é perdido (termólise) para o meio ambiente sem prejuízo apreciável ao seu rendimento. O aumento da temperatura ambiente e do estresse calórico eleva a secreção do hormônio cortisol (Starling et al., 2005).

O fluxo de dissipação de calor ocorre através de processos que dependem da temperatura ambiental (condução, convecção e radiação) e da umidade (evaporação via transpiração e respiração). A hipertermia ocorre quando o fluxo de calor para o ambiente é menor que a produção de calor metabólico. Quando a temperatura do ar (TA) se eleva e o gradiente térmico entre a superfície do corpo e o meio, decresce, dificultando a dissipação de calor, tendo o animal que lançar mão de mecanismos evaporativos (sudorese e/ou frequência respiratória) para perder calor (SOUZA et al., 2008). 
LUZ, C.S.M. et al. Parâmetros termorreguladores e variáveis ambientais de ovinos em diferentes épocas do ano no sul do estado do Piauí. PUBVET, Londrina, V. 6, N. 35, Ed. 222, Art. 1474, 2012.

Em altas temperaturas os ovinos reduzem a ingestão de alimentos e aumentam o consumo de água na tentativa de dissipar o calor corporal. 0 aumento da temperatura da pele, a elevação da temperatura retal, o aumento da frequência respiratória, a diminuição da ingestão de alimentos e redução do nível de produção são indicadores diretos do estresse calórico (ANDRADE et al., 2006). O objetivo desse trabalho foi de avaliar as características termorreguladoras de ovinos das raças Santa Inês e Morada Nova em duas épocas no município de Bom Jesus - PI, bem como correlacionar estes dados com algumas variáveis meteorológicas.

\section{Material e métodos}

O projeto foi desenvolvido no Campus Professora Cinobelina Elvas - Bom Jesus da Universidade Federal do Piauí e contou com a participação de alunos da graduação, professores e técnicos de diferentes áreas. Os animais utilizados são da espécie: Ovis aires, no qual a pesquisa foi realizada no setor de ovinocultura da Universidade Federal do Piauí, onde verifica-se a ocorrência de um período chuvoso, geralmente de janeiro a maio, além de um período de estiagem de junho a novembro.

Foram escolhidos aleatoriamente 10 animais, sendo cinco da raça Santa Inês e cinco Morada Nova, de seis a um ano e meio de idade, com peso médio de 20 a $35 \mathrm{~kg}$, aptidão para produção de carne, de ambos os sexos e pêlos claros e pele pigmentada. Os animais são criados em sistema de confinamento com suplementação no cocho.

Os dados foram coletados semanalmente durante os meses de agosto a novembro de 2011, correspondentes ao período seco, e de janeiro a abril de 2012, correspondentes ao período chuvoso. Foram realizadas duas coletas diárias: pela manhã, das 9:00 h às 10:00 h e pela tarde, das 15:00 h às 16:00 h. Nos animais foram registradas inicialmente a frequência respiratória (FR), em movimentos respiratórios por minuto, através da observação direta dos movimentos dos flancos esquerdo; em seguida registrou-se a temperatura retal (TR), por meio de um termômetro clínico introduzido diretamente no reto 
LUZ, C.S.M. et al. Parâmetros termorreguladores e variáveis ambientais de ovinos em diferentes épocas do ano no sul do estado do Piauí. PUBVET, Londrina, V. 6, N. 35, Ed. 222, Art. 1474, 2012.

dos animais durante dois minutos. Posteriormente foi estimada a taxa da sudação (TS), pelo método calorimétrico de Schleger e Turner (1965), adaptado por Silva (2000).

No ambiente foram registradas as temperaturas do termômetro de bulbo seco temperatura do ar (TA) e do termômetro de bulbo úmido, no início e fim de cada coleta, com as quais foi estimada a umidade do ar (UA); Nesses mesmos horários foram registradas as temperaturas do termômetro de globo negro, com as quais se calculou o Índice de Temperatura de Globo e Umidade (ITGU), segundo metodologia usada por Morais (2008), através das equações a seguir:

\section{Pressão Parcial de Vapor $(\operatorname{Pp}\{T a\})$}

$\mathrm{Pp}\{\mathrm{Ta}\}=\operatorname{Ps}\{\mathrm{Tu}\}-\mathrm{Y}(\mathrm{Ta}-\mathrm{Tu})$

\section{Sendo:}

$\operatorname{Ps}\{\mathrm{Tu}\}=$ pressão de saturação à temperatura $\mathrm{Tu}(\mathrm{kPa})$

$\mathrm{Y}=$ constante psicrométrica, $\left(\mathrm{kPa} /{ }^{\circ} \mathrm{C}\right)$

$\mathrm{Ta}=$ temperatura do ar ou de bulbo seco $\left({ }^{\circ} \mathrm{C}\right)$

$\mathrm{Tu}=$ temperatura do bulbo úmido $\left({ }^{\circ} \mathrm{C}\right)$

Índice de Temperatura de Globo e Umidade (ITGU)

ITGU $=\mathrm{Tg}+0,36 \mathrm{Tpo}+41,5$

Sendo:

$\mathrm{Tg}=$ temperatura do termômetro de globo $\left({ }^{\circ} \mathrm{C}\right)$

Tpo $=$ temperatura do ponto de orvalho $\left({ }^{\circ} \mathrm{C}\right)$

$41,5=$ constante

Os dados foram submetidos a teste de homogeneidades de variância do resíduo, análises de variância e de correlação entre as variáveis analisadas. Para comparar os resultados foi realizado o teste de Tukey $(P<0,05)$, utilizando-se o pacote estatístico SAS, versão 9.3 (SAS Institute, 2003). A análise estatística foi realizada pelo método dos quadrados mínimos, conforme Harvey (1960), tendo como base o seguinte modelo: 
LUZ, C.S.M. et al. Parâmetros termorreguladores e variáveis ambientais de ovinos em diferentes épocas do ano no sul do estado do Piauí. PUBVET, Londrina, V. 6, N. 35, Ed. 222, Art. 1474, 2012.

$$
Y_{i j k l m}=\mu+A_{j i}+H_{k}+E_{l}+I T G U_{i j k l}+F R_{i j k l}+T R_{i j k l}+e_{i j k l m}
$$

Sendo:

$\mathrm{Y}_{\mathrm{ijk} \mathrm{m}}=\mathrm{m}$-ésima média

$\mu=$ é a média geral;

$\mathrm{A}_{\mathrm{ji}}=$ efeito aleatório do j-ésimo animal pertencente a i-ésima raça;

$H_{k}=$ é o efeito fixo do k-ésimo horário de coleta $(k=1,2)$;

$E_{I}=$ é o efeito fixo do l-ésima época de coleta $(k=1,2)$;

$\mathrm{ITGU}_{\mathrm{ijkl}}=$ Índice de Temperatura de Globo e Umidade da I-ésima coleta, jésimo animal pertencente ao i-ésima raça

$\mathrm{FR}_{\mathrm{ijkl}}=$ frequência respiratória da l-ésima coleta, j-ésimo animal pertencente ao i-ésima raça

$\mathrm{TR}_{\mathrm{ijkl}}=$ Taxa de sudação da I-ésima coleta, j-ésimo animal pertencente ao i-ésima raça

$e_{i j k l m}$ é o resíduo, incluindo o erro aleatório.

Os efeitos das instalações, do consumo de alimentos e da água sobre os animais foram considerados a taxa de sudação (TS) que para sua mensuração, utilizou-se papel filtro no 01 furado com auxilio de um furador manual de papel apresentando $0,5 \mathrm{~cm}$ de diâmetro por disco, sendo logo depois imerso em solução aquosa a $10 \%$ de cloreto de cobalto, em seguida secado na estufa a $105^{\circ} \mathrm{C}$ por $3 \mathrm{~h}$, quando seco, apresentou cor azul violeta intenso. Três desses discos foram montados sobre lâminas de microscópios e nelas fixados com fita adesiva transparente tipo "durex". Essas lâminas foram guardadas em um dissecador para proteção contra a umidade do ar, pois ao passo que ganha umidade passa a ter a coloração rosa-clara.

As lâminas foram preparadas no máximo com $12 \mathrm{~h}$ de antecedência de uso. Com o auxilio de uma lâmina de bisturi, foi feita a tricotomia nos animais na parte dorsal do costado do lado direito de cada animal. Após a limpeza da gordura e sujeira que foi realizada com álcool e papel toalha, foi fixada a fita adesiva com os três discos e começava a contagem do tempo para que fosse possível saber o tempo de cada viragem, sendo cada disco controlado de forma 
LUZ, C.S.M. et al. Parâmetros termorreguladores e variáveis ambientais de ovinos em diferentes épocas do ano no sul do estado do Piauí. PUBVET, Londrina, V. 6, N. 35, Ed. 222, Art. 1474, 2012.

separada em cada tempo de viragem em segundos.

\section{Resultados e discussão}

Os resultados apresentados na tabela 1 a TA (temperatura do ar) apresentou diferença a significativa a $5 \%$ pelo teste tukey, entre a manhã do período chuvoso e a tarde do período seco, com superioridade para o horário mais seco do dia que foi registrado no turno da tarde do período seco, provavelmente devido à maior incidência de radiação solar verificada. A resistência de um animal às altas temperaturas é definida pela sua maior ou menor capacidade em dissipar o calor corporal excessivo, conseguindo assim manter a sua temperatura corporal média dentro dos limites da homeotermia (Medeiros et al., 2007).

Tabela 1 - Médias das variáveis meteorológicas e índices de conforto térmico de ovinos da raça Santa Inês e Morada nova durante os turnos da (manhã e tarde) nos períodos (seco e chuvoso), em Bom Jesus-PI.

\begin{tabular}{lllll}
\hline Características & \multicolumn{2}{c}{ Período Seco } & \multicolumn{2}{c}{ Período Chuvoso } \\
& Manhã & Tarde & Manhã & Tarde \\
\hline TA ( $\left.{ }^{\circ} \mathrm{C}\right)$ & $26,27^{\mathrm{ab}}$ & $28,27^{\mathrm{a}}$ & $22,10^{\mathrm{b}}$ & $27,74^{\mathrm{ab}}$ \\
UA (KPa) & $41,07^{\mathrm{b}}$ & $40,88^{\mathrm{b}}$ & $96,50^{\mathrm{a}}$ & $72,60^{\mathrm{ab}}$ \\
ITGU ( $\left.{ }^{\circ} \mathrm{C}\right)$ & $91,18^{\mathrm{a}}$ & $95,55^{\mathrm{a}}$ & $77,46^{\mathrm{b}}$ & $78,15^{\mathrm{b}}$ \\
\hline
\end{tabular}

Médias seguidas de mesma letra na linha não diferem pelo Teste de Tukey ao nível de $5 \%$ de significância. Temperatura do ar (TA); Umidade do Ar (UA); Índice de Temperatura Globo e Umidade (ITGU).

A UA apresentou diferença entre períodos, mas não houve diferença a $(P>0,05)$ para os turnos do período seco, no entanto, foi constatada uma grande diferença entre períodos, pois, no turno da tarde do período seco a UA apresentou uma magnitude de $(40,88 \mathrm{KPa})$ e na manhã do período chuvoso apresentou magnitude de $(96,50 \mathrm{KPa})$ mostrando assim uma maior quantidade de gotículas de água presentes no ar nos horários mais frios do período chuvoso. Com relação a TA houve diferença significativa $(P<0,05)$ tanto para período quanto para turno, onde os maiores valores foram obtidos no período seco e no turno da tarde (tabela 1). Em ambiente de sombra, o ITGU 
LUZ, C.S.M. et al. Parâmetros termorreguladores e variáveis ambientais de ovinos em diferentes épocas do ano no sul do estado do Piauí. PUBVET, Londrina, V. 6, N. 35, Ed. 222, Art. 1474, 2012.

registrado, mostrou diferença pelo Teste de Tukey ao nível de 5\% de significância somente nos períodos, devido a altos valores de umidade do ar combinados as temperaturas ambientais baixas.

O clima tropical e seco do nordeste provoca nos animais estresse calórico, devido à dificuldade de realizar trocas térmicas por evaporação, sobretudo, a cutânea. Bezerra (2011) encontrou valores semelhantes para o período chuvoso $\left(78,93^{\circ} \mathrm{C}\right)$ e valores inferiores para o período seco $(80,24)$, isso indica que o período seco é bastante crítico para a homeotermia dos animais, pois podem vir a suprimir as perdas de calor latente.

A alta temperatura ambiente que ocorre comumente no período seco do ano na região, tem sido considerada estressante para os animais (ROCHA et al., 2009), mas constatou-se que nas condições ambientais verificadas durante a condução dessa pesquisa, a homeotermia por vasodilatação periférica tenderia a apresentar eficiência relativamente baixa, pois o gradiente entre a temperatura corporal e a ambiental foi pequeno, limitando assim o fluxo de calor por processo não-evaporativo (condução, convecção e radiação), conforme afirma Silva (2000) e também Sousa Jr (2008) ser necessário para esse processo se mostrar eficiente. Porém, não deve ser desconsiderado o fato da umidade relativa se apresentar sempre baixa nessa época do ano, com isso facilitaria a perda de calor pela sudorese.

As médias das variáveis termorreguladoras dos animais estudados estão apresentadas na Tabela 2. Não foi verificada diferença significativa $(P>0,05)$ para nenhuma das variáveis avaliadas nos turnos do período chuvoso, devido ao conforto térmico proporcionado pelas instalações aos quais os animais foram mantidos e também devido ao acondicionamento que é feito em ambiente de sombra com ração suplementada. 
LUZ, C.S.M. et al. Parâmetros termorreguladores e variáveis ambientais de ovinos em diferentes épocas do ano no sul do estado do Piauí. PUBVET, Londrina, V. 6, N. 35, Ed. 222, Art. 1474, 2012.

Tabela 2 - Média de temperatura retal, frequência respiratória e taxa de sudação de ovinos da raça Santa Inês e Morada nova durante os turnos da (manhã e tarde) e nos períodos (seco e chuvoso), em Bom Jesus-PI.

\begin{tabular}{lcccc}
\hline Características & \multicolumn{2}{c}{ Período Seco } & \multicolumn{2}{c}{ Período Chuvoso } \\
& Manhã & Tarde & Manhã & Tarde \\
\hline FR (mov./mim.) & $58,75^{\mathrm{a}}$ & $55,79^{\mathrm{a}}$ & $56,35^{\mathrm{a}}$ & $55,17^{\mathrm{a}}$ \\
TR $\left({ }^{\circ} \mathrm{C}\right)$ & $38,85^{\mathrm{ab}}$ & $39,40^{\mathrm{a}}$ & $38,68^{\mathrm{b}}$ & $38,91^{\mathrm{ab}}$ \\
TS $(\mathrm{g} / \mathrm{m} / \mathrm{h})$ & $98,03^{\mathrm{a}}$ & $55,89^{\mathrm{a}}$ & $51,21^{\mathrm{a}}$ & $41,92^{\mathrm{a}}$ \\
\hline
\end{tabular}

Médias seguidas de mesma letra na linha não diferem pelo Teste de Tukey ao nível de $5 \%$ de significância. Frequencia Respiratória (FR); Temperatura Retal (TR); Taxa de Sudação (TS).

Considerando a FR, pôde-se observar que no turno da manhã do período seco $(58,75)$, obteve essa magnitude devido à alta temperatura no período seco e provavelmente devido o período da manhã ser mais favorável a esse mecanismo termorregulador em prol da sua. Ocorreu aumento da FR como forma de dissipação de calor, para manter a homeotermia (GOMES et al., 2008; PERISSINOTO et al., 2009).

A TR é o mecanismo de dissipação de calor mais utilizado nas condições estudadas, possivelmente pelos animais não apresentarem condições fisiológicas mais eficientes para dissipação de calor por outros mecanismos, o que dificulta a perda de calor, aquecendo mais o corpo destes animais. A vantagem da evaporação é que não depende de um diferencial de temperatura, tal como a condução, a convecção e a radiação, mas sim do diferencial de pressão de vapor entre a atmosfera e a superfície em questão (OLIVEIRA, 2007). É importante salientar que sendo os ovinos predominantemente de pelos escuros, isso pode ter favorecido a maior estocagem de calor, devido à maior absorção de calor ambiente, aumentando a temperatura corporal dos animais.

Para os valores de TR houve diferença significativa a $(P<0,05)$, para os turnos, onde percebemos que os turnos do período seco proporcionou um maior aquecimento corporal, isso provocado pelo acionamento desse mecanismo termorregulador nos horários de maior aporte de calor buscando a 
LUZ, C.S.M. et al. Parâmetros termorreguladores e variáveis ambientais de ovinos em diferentes épocas do ano no sul do estado do Piauí. PUBVET, Londrina, V. 6, N. 35, Ed. 222, Art. 1474, 2012.

zona de equilíbrio térmico. No período seco a temperatura da tarde $\left(39,40^{\circ} \mathrm{C}\right)$ foi superior à temperatura retal da manhã $\left(38,85^{\circ} \mathrm{C}\right)$. Valores superiores foram encontrados por Cezar $(2004)$ que foram $\left(40,0^{\circ} \mathrm{C}\right)$ e $\left(39,5^{\circ} \mathrm{C}\right)$ correspondentes aos turnos da manhã e tarde, respectivamente significando que os ovinos da raça Dorper mantidos em regime semi-intensivo, sob luminosidade natural, alimentados a pasto, com suplementação concentrada e mineral mais água ad libitum, não foram capazes de dissipar todo o calor necessário para manter sua temperatura corporal dentro do limite basal médio $\left(39,1^{\circ} \mathrm{C}\right)$, principalmente durante o período da tarde.

A TS não diferenciou $(P>0,05)$, mas mostrou magnitude no período seco devido à grande incidência de raios solares nesse período e as altas temperaturas do ar, apresentando assim, uma variação de sua capacidade sudativa, ou seja, os animais apresentaram valores de taxas de sudação semelhantes durante os dias mais ensolarados. A TS é um mecanismo fisiológico que é utilizado para dissipar a temperatura superficial pelas glândulas sudoríparas, e se torna bastante eficiente quando a temperatura está alta e a umidade baixa. Segundo Ligeiro (2006) a capacidade máxima de sudação é atingida sob temperaturas elevadas e umidade baixa, quando ocorre aumento do volume de sangue para a epiderme, que proporciona maior estímulo para produção das glândulas sudoríparas.

\section{Conclusão}

Constatou-se nesse estudo que os ovinos mostraram-se adaptados em relação às mudanças climáticas de período, contudo, apresentaram maior aquecimento corporal e termólise evaporativa nos turnos da tarde, tanto do período seco quanto do chuvoso, isso devido à incidência de raios solares terem sido mais intensos e a umidade do ar ter sido menor em ambos os períodos.

Mediante a todo o estudo constatamos que no período chuvoso os animais perdem mais calor por vias evaporativas e no período da manhã e nos 
LUZ, C.S.M. et al. Parâmetros termorreguladores e variáveis ambientais de ovinos em diferentes épocas do ano no sul do estado do Piauí. PUBVET, Londrina, V. 6, N. 35, Ed. 222, Art. 1474, 2012.

turnos da tarde houve maior aquecimento corporal, isso devido a menor temperatura no turno da manhã e menor umidade do ar á tarde.

\section{Referências Bibliográficas}

BEZERRA, W. M. A. X.; SOUZA, B. B.; SOUSA W. H.; CUNHA M. G. G.; BENICIO T. M. A. Comportamento fisiológico de diferentes grupos genéticos de ovinos criados no semiárido paraibano. Revista Caatinga, Mossoró, v. 24, n. 1, p. 130-136, jan.-mar., 2011.

CEZAR, M. F. et al. Avaliação de parâmetros fisiológicos de ovinos dorper, Santa Inês e seus mestiços perante condições climáticas do trópico semi-árido nordestino. Revista Agrotecnica, Lavras, v. 28, n. 3, p. 614-620, maio/jun., 2004.

GOMES, C. A. V.; FURTADO, D. A.; MEDEIROS, N. A.; SILVA, D. S.; PIMENTA FILHO, E. C.; LIMA JÚNIOR, V. Efeito do ambiente térmico e níveis de suplementação nos parâmetros fisiológicos de caprinos Moxotó. Revista Brasileira de Engenharia Agrícola e Ambiental, v.12, n.2, p.213-219, 2008.

HARVEY, W. R. Least squares analysis of data with unequal suclass numbers. Beltsville, Md: ARS/USDA, Publ. 1960.

IBGE - Instituto Brasileiro de Geografia e Estatística. Censo Agropecuário, Brasil, 2010.

LIGEIRO, E. C.; MAIA, A. S. C.; SILVA, R. G.; LOUREIRO, C. M. B. Perda de calor por evaporação cutânea associada às características morfológicas do pelame de cabras leiteiras criadas em ambiente tropical. Revista Brasileira de Zootecnia, Viçosa, v.35, n.2, p.544549, 2006.

Medeiros, L. F. D.; VIERIRA, D. H.; OliVeirA, C. A.; FONSECA, C. E. M.; PEDROSA, I. A.; GUERSON, F. D.; PEREIRA, V. V.; MADEIRO, A. S. Avaliação de parâmetros fisiológicos de caprinos SPRD (sem padrão racial definido) pretos e brancos de diferentes idades, à sombra, no município do Rio de Janeiro, RJ. B. Indústr. Anim., N. Odessa, v. 64, n. 4, p. 277-287, 2007.

MORAIS, D. A. E. F.; MAIA, A. S. C.; SILVA, R. G. et al. Variação anual de hormônios tireoideanos e características termorreguladoras de vacas leiteiras em ambiente quente. Revista Brasileira de Zootecnia, v.37, n.3, p.538-545, 2008.

OLIVEIRA, A. L. Mecanismos termorreguladores de cabras da raça Saanen. 2007. Tese (Doutorado) - Faculdade de Ciências Agrárias e Veterinárias - Unesp, Jaboticabal, São Paulo.

PERISSINOTTO, M.; MOURA, D. J.; CRUZ, V. F.; SOUZA, S. R. L.; LIMA, K. A. O.; MENDES, A. S. Conforto térmico de bovinos leiteiros confinados em clima subtropical e mediterrâneo pela análise de parâmetros fisiológicos utilizando a teoria dos conjuntos fuzzy. Ciência Rural, v.39, n.5, p.1492-1498, 2009.

ROCHA, R. R. C.; COSTA, A. P. R.; AZEVEDO, D. M. M. R.; NASCIMENTO, H. T. S.; CARDOSO, F. S.; MURATORI, M. C. S.; LOPES, J. B. Adaptabilidade climática de caprinos Saanen e Azul no meio-norte do Brasil. Arquivo Brasileiro de Medicina Veterinária e Zootecnia, v.61, n.5, p.1165-1172, 2009.

SAS Institute, SAS (Statistical Analysis System). User's Guide. Cary, NC: SAS Institute Inc., 129p. 2003. 
SILVA, R. G. Introdução à Bioclimatologia Animal. São Paulo: Nobel, 286p 2000.

SOUSA Jr, S. C.; MORAIS, D. E. F.; VASCONCELOS, A. M et al. Caracterísicas Termorreguladoras de Caprinos, Ovinos e Bovinos em Diferentes Épocas do Ano em Região SemiÁrida. Revista Científica de Produção Animal., v.10, n.2, p.127-137, 2008.

SOUZA, B. B.; SOUZA, E. D.; CEZAR, M. F.; SOUZA, W. H.; SANTOS, J. R. S.; BENÍCIO, T. M. A. Temperatura superficial e índice de tolerância ao calor de caprinos de diferentes grupos raciais no semiárido paraibano. Ciênc. Agrotec., Lavras, v. 32, n. 1, p. 275-280, 2008.

STARLING, J.M.C.; SILVA, R.G.; NEGRÃO, J.A. et al. Variação estacional dos hormônios tireoideanos e do cortisol em ovinos em ambiente tropical. Revista Brasileira de Zootecnia, v.34, n.6, p.2064-2073, 2005.

ANDRADE, I. S.; SOUZA, B. B.; PEREIRA FILHO, J. M.; SILVA, A. M. A. Parâmetros fisiológicos e desempenho de ovinos Santa Inês submetidos a diferentes tipos de sombreamento e a suplementação em pastejo. Ciência e Agrotecnologia, v.31, n.2, p.540-547, 2006.

SCHLEGER, A. V.; TURNER, H. G. Sweating rates of cattle in the field and their reaction to diurnal and seasonal changes. Australian Journal Agricultural Research, v.16, p. 92-106. 1965. 